\title{
Green Extraction: Enhanced Extraction Yield of Asiatic Acid from Centella asiatica (L.) Nanopowders
}

\author{
M. Z. Borhan, ${ }^{1,2,3}$ R. Ahmad, ${ }^{3}$ M. Rusop, ${ }^{1,2}$ and S. Abdullah ${ }^{2}$ \\ ${ }^{1}$ NANO-SciTech Centre (NST), Institute of Science, Universiti Teknologi MARA (UiTM), Selangor, 40450 Shah Alam, Malaysia \\ ${ }^{2}$ NANO-Innovation Centre (Nano-IC), Faculty of Applied Sciences, Universiti Teknologi MARA (UiTM), Selangor, \\ 40450 Shah Alam, Malaysia \\ ${ }^{3}$ Faculty of Applied Sciences, Universiti Teknologi MARA (UiTM), Selangor, 40450 Shah Alam, Malaysia
}

Correspondence should be addressed to M. Z. Borhan; mzborhan@yahoo.com

Received 29 May 2013; Revised 4 September 2013; Accepted 24 October 2013

Academic Editor: Rassoul Dinarvand

Copyright (C) 2013 M. Z. Borhan et al. This is an open access article distributed under the Creative Commons Attribution License, which permits unrestricted use, distribution, and reproduction in any medium, provided the original work is properly cited.

Nanopowders of Centella asiatica (L.) were produced using planetary ball mill in order to investigate the differences of water extraction yield of asiatic acid as compared to micropowders of Centella asiatica. Effect of extraction time (20-60 min) on extraction yield of asiatic acid from Centella asiatica was examined. Results showed that water extraction of asiatic acid using Centella asiatica nanopowders exhibits was almost $50 \%$ higher extraction yield with $7.09 \mathrm{mg} / \mathrm{g}$ as compared to the micropowders of Centella asiatica. It was concluded that nanopowders contributed in enhancing water extraction yield of asiatic acid as compared to micropowders. Thereby utilizing nanopowders in water extraction could improve the extraction of asiatic acid via clean, eco-friendly, and less expensive process.

\section{Introduction}

Centella asiatica (L.) is one of the medicinal plants that has been declared to have a variety of medicinal effects. Its bioactive compounds include asiatic acid, asiaticoside, madecassic acid, and madecassoside. Asiaticoside (Figure 1(a)) is the principal bioactive ingredient among them since asiaticoside gave a better effect on antibacterial and fungicidal activity against bacteria and fungi [1]. Asiatic acid (Figure 1(b)) also displays good biological effects such as promoting collagen synthesis stimulating extracellular matrix accumulation, and promoting fibroblast proliferation in a rat wound model [2].

Asiatic acid is an aglycone form of asiaticoside and easily formed by hydrolyzing the sugar moiety of asiaticoside structure in acid condition. Therefore, some data suggest that the therapeutic effect of asiaticoside may come from asiatic acid [3]. Some studies show the significance of sugar moiety in the structure of asiaticoside which may enhance the bioavailability of asiatic acid compared to the only aglycone structure alone [4]. But once again, enriching asiatic acid in the extract is important since all the synthesizing alkyl groups require hydrolyzing of asiaticoside first prior modification of asiatic acid functional groups [4]. By modification, the asiatic acid may provide us with data in relationship between structural and hepatoprotetive properties in order to develop new novel drugs for treating disease $[5,6]$.

Extraction of active chemical compounds from natural sources is a most important research area in pharmaceutical and chemical industry. Bioactive compound extraction aims to get a better extraction yield and less time consuming without altering the structure of compounds extracted. Large organic solvents consumption in extraction process is the main problem in conventional extraction process. In conventional extraction, the usage of organic solvent is mandatory; as a result, large amount of chemical waste was dumped and affected the environmental. Clean extraction techniques have been encouraged by government, health, and environmental regulations due to environment concern. Recently, clean extraction methods such as pressurized hot water extraction (PHWE), supercritical/subcritical water extraction (SFE), and ultrasonic-assisted extraction (UAE) have been introduced to overcome toxicity problem 


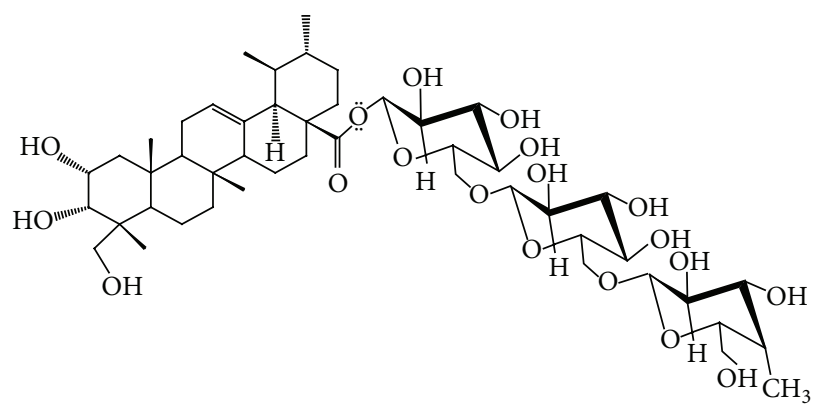

(a)

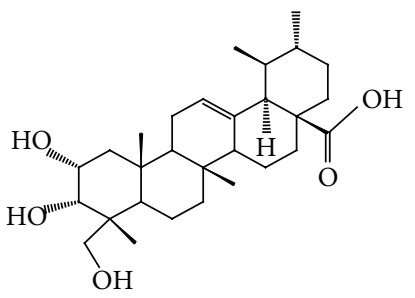

(b)

Figure 1: Chemical structure of (a) asiaticoside and (b) asiatic acid.

encountered in the extraction industry [7-9]. However, the extraction efficiency of these methods is greatly dependent on the particles size of plant material. Among the methods, ultrasonic-assisted extraction (UAE) has been known for its simplicity such as short processing time and low solvent consumption [10].

Herbal nanopowders are the herbal powders ranging from 10 to $1000 \mathrm{~nm}$ in size. This nanopowder has unique properties such as larger surface area, thus improving dissolve-out properties of bioactive components in the cellular matrix. Several studies have shown increase of extraction ratio of bioactive components from 17 to $50 \%$ increases compared to the normal powders [11, 12]. Beside a better extraction yield, the extraction of nanopowders does not require longer extraction time. Thus, it will save time consumed for extraction and more than that it just only requires small portion of powder. Thus, it is cost effective and concerned with the limited supply of raw material of herbal plant itself [13].

In this study, we investigated the effectiveness of nanopowders compared to the micropowders for the water extraction of asiatic acid from Centella asiatica assisted by the ultrasonic probe. The influence of extraction time also has been investigated in order to define the optimal condition for extraction.

\section{Methodology}

2.1. Chemicals and Materials. Asiaticoside was purchased from Chengdu Biopurify, China; asiatic acid standard was purchased from the Sigma Aldrich; acetonitrile (LC grade) from Fisher Chemicals; and methanol (HPLC grade) from Friedemann Schmidt. Distilled water was purified using a Milli-Q water purification system (Millipore, Bedford, MA, USA).

2.2. Sample Preparation. Plant material was bought from local market in Tanjung Malim, Perak, Malaysia, during March 2010. Centella asiatica was washed with running tap water and rinsed by distilled water to remove any dirt and contaminant on the plant material. Then, cleaned plant material was stored in the $50^{\circ} \mathrm{C}$ controlled oven and left to dry for 3 days. The dried plant material was ground using conventional rotor. The ground powder was sieved through $250 \mu \mathrm{m}$ sieve and stored in the $4^{\circ} \mathrm{C}$ prior ball milling process.

2.3. Production of Centella asiatica Nanopowders. The dried and powdered plant material $(0.3 \mathrm{~g})$ first was mixed with $25 \mathrm{~mL}$ of $0.1 \%$ (w/v) Pluronic F127 and milled at 1.2\%, w/v of mass concentration, and $550 \mathrm{rpm}$ milling speed at 4 hours of milling time in the $50 \mathrm{~cm}^{3}$ stainless steel jar containing 25 gram of $2 \mathrm{~mm}$ diameter size of zirconia bead. These parameters were chosen because that the early preliminary results show at these conditions, the content of asiatic acid is highest among nanopowders produced at difference conditions of grinding (mass concentration, milling time, and amount of bead). The resulting milling product was in the form of nanosuspension. This nanosuspension was further used for extraction.

2.4. Particles Size Analysis and Morphology. Prior to the measurement, nanosuspensions of each sample were taken out and adjusted to $0.01 \%(\mathrm{w} / \mathrm{v})$ concentration and introduced into a disposable cuvette to be measured in triplicate. ZAverage and polydispersity (PdI) were recorded. FESEM (Carl Zeiss SMT SUPRA 40VP) imaging was carried out by placing $10 \mu \mathrm{L}$ nanosuspension onto a glass slide and stored in an electronic desiccators (temperature: $20^{\circ} \mathrm{C}$, humidity: $18 \%$ $\mathrm{RH})$ for drying purpose. The dried samples were then coated with gold ( $\sim 10 \mathrm{~nm}$ thick) and were placed onto an adhesive tape on the FESEM stub.

\subsection{HPLC Analysis}

2.5.1. Extraction. A $0.6 \mathrm{~g}$ micropowder was weighed and mixed with $50 \mathrm{~mL}$ water. Then, this mixture was sonicated for 20, 40, and 60 minutes by ultrasonic processor (UP400S Ultrasonic Processor Hielscher) at frequencies, wattage output, and $125 \mathrm{~W}$. Then, mixture was centrifuged to separate the particles and filtered by gravitational filtration. Filtrate was collected and water was removed by freeze dryer and weights of crude extracts were recorded. The extracts were dissolved in methanol to $1 \mathrm{mg} / \mathrm{mL}$ and filtered through $0.22 \mu \mathrm{m}$ filter paper before being subjected to HPLC analysis. The nanopowders were also extracted in the same manner as above. 


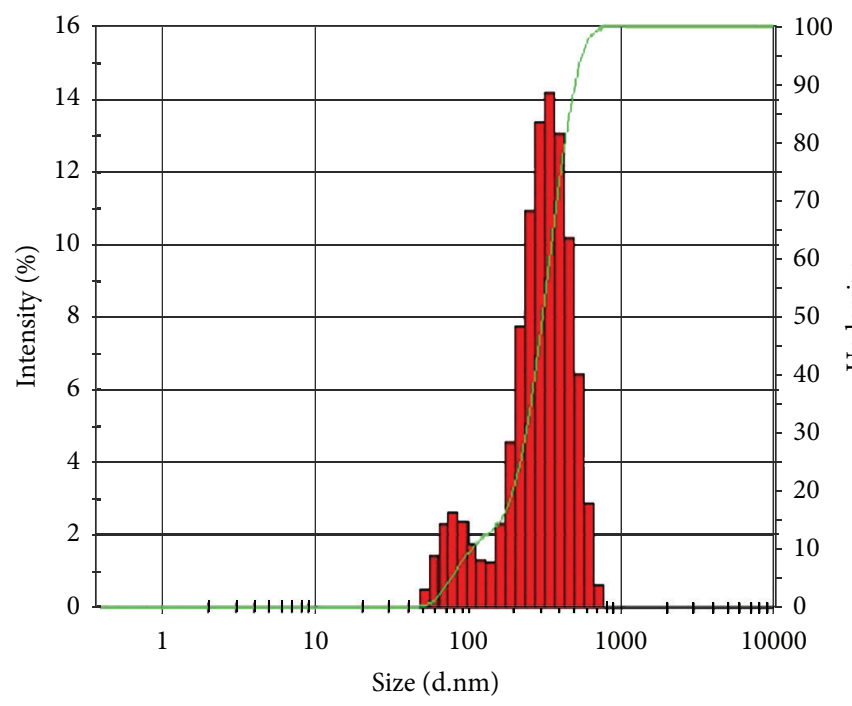

(a)

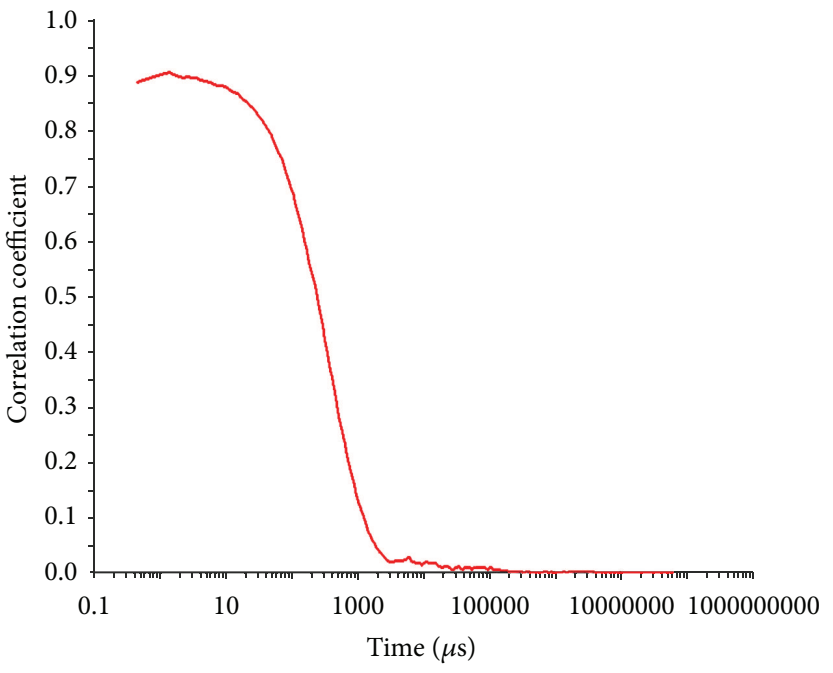

(b)

Figure 2: Particles size analysis of nanopowder: (a) size distribution; (b) correlogram.

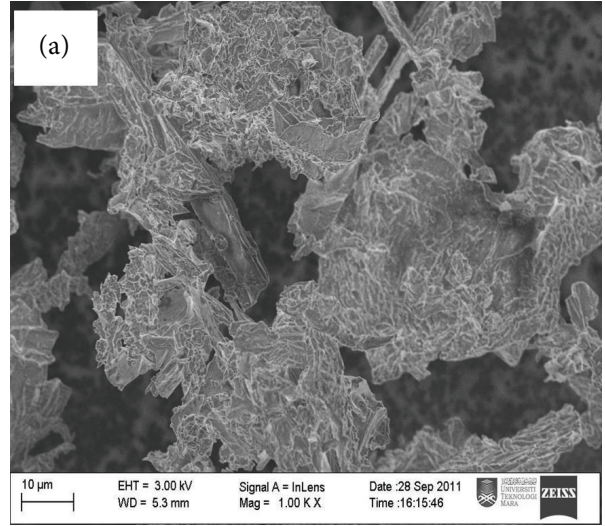

(a)

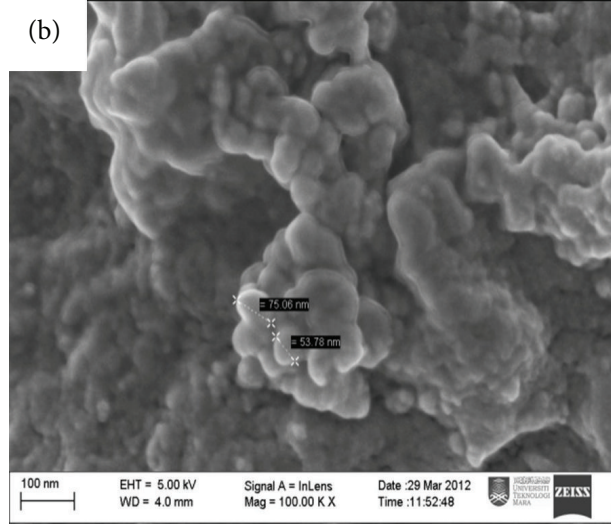

(b)

FIGURE 3: FESEM micrographs of Centella asiatica: (a) raw powder; (b) nanopowders.

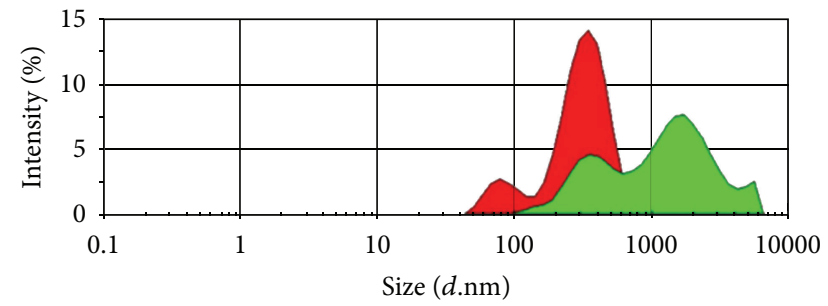

FIGURE 4: Size distribution of nanopowders (red curve-nanopowders in suspension; green curve-freeze-dried nanopowders).

2.5.2. HPLC Condition. Individual's content in the extract was analysed using HPLC analysis. The separation was performed on an Agilent 1200 HPLC (Agilent, USA) with a Zorbax Eclipse XDB-C18 $(4.6 \mathrm{~mm} \times 150 \mathrm{~mm}, 5 \mu \mathrm{m})$. Solvent
A (methanol) and solvent B (acetonitrile) were selected as the mobile phases. Gradient elution was used as follows: $0 \mathrm{~min}, 80: 20 ; 30 \mathrm{~min}, 45: 55$. The injection volume was $40 \mu \mathrm{L}$, the flow rate was $1.0 \mathrm{~mL} / \mathrm{min}$, and the column temperature was maintained at $25^{\circ} \mathrm{C}$. Sample was introduced into the HPLC using an Agilent 1200 G1367B autosampler. The signal was monitored at $206 \mathrm{~nm}$ using the diode array detector (Agilent, USA). The peaks were characterized by comparing the retention time with the standards. Retention times for asiaticoside and asiatic acid were approximately 8.807 and 23.809 mins, respectively. Asiatic acid and asiaticoside standard stock solution were prepared by dissolving approximately $10 \mathrm{mg}$ each of accurately weighed pure compound in $10 \mathrm{~mL}$ methanol-water $(9: 1)$, respectively. Standard working solutions used for calibration were prepared by diluting the above standard solutions with methanol to the desired concentrations $(10-100 \mu \mathrm{g} / \mathrm{mL})$. All standard solutions were 


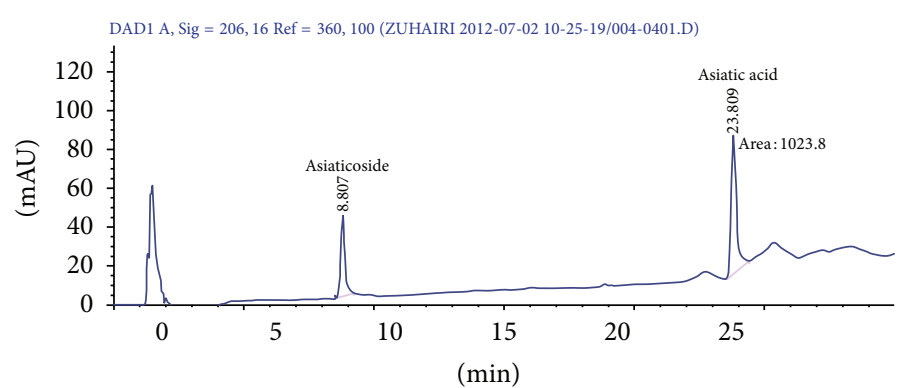

(a)

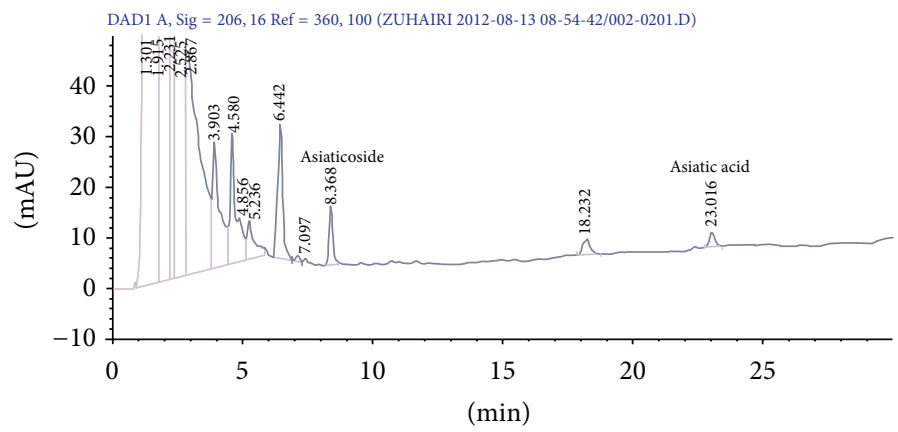

(b)

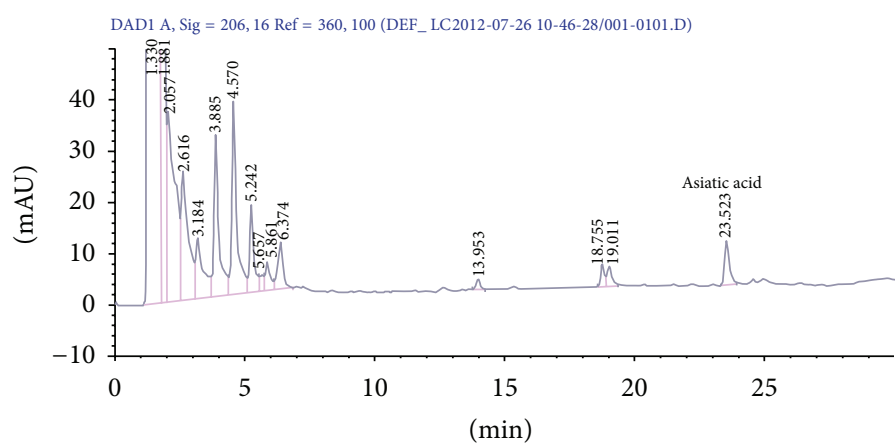

(c)

FiguRE 5: HPLC chromatogram: (a) mixture standards; (b) micropowders extract; (c) nanopowders extract.

analyzed in triplicate and the average peak areas were measured. UV peak areas of the external standards $(y)$ were plotted against the corresponding concentrations $(x, \mu \mathrm{g} / \mathrm{mL})$ to generate standard curves: $y=12.22 x-0.296$ was for asiatic acid $\left(r^{2}=0.994\right)$ and $y=6.191 x-2.125$ was for asiaticoside $\left(r^{2}=0.994\right)$. The content of each compound $(\mu \mathrm{g} / \mathrm{mL})$ in the extracts was then calculated from the experimental peak areas by interpolation to standard calibration curves.

2.6. Extraction Yields Determination. The extraction yields of asiatic acid and asiaticoside were calculated using the following:

Yield $\left(\frac{\mathrm{mg}}{\mathrm{g}}\right)=\frac{\text { weight of asiatic acid }(\mathrm{mg})}{\text { weight of dried sample }(\mathrm{g})}$.
The percentage total asiatic acid and asiaticoside extraction yield in nanopowders over micropowders were calculated as follows:

\% Extraction yield

$=\left((\text { Total asiatic acid }+ \text { asiaticoside })_{N}\right.$

$\left.-(\text { Total asiatic acid }+ \text { asiaticoside })_{M}\right)$

$\times\left((\text { Total asiatic acid }+ \text { asiaticoside })_{M}\right)^{-1}$

$\times 100 \%$,

where $N$ is nanopowders and $M$ is micropowders.

\section{Results and Discussions}

3.1. Particles Size Analysis and Surface Morphology. The average size of the nanoparticles was determined as $285 \mathrm{~nm}$ 
as shown in Figure 2(a). The ground nanoparticle sizes varied from $50 \mathrm{~nm}$ to $800 \mathrm{~nm}$ with the $342 \mathrm{~nm}$ being the highest size amount with $14 \%$ of intensity. The correlation coefficient shown in Figure 2(b) shows a good correlation of analysis with interception of $y=$ axis around 0.9 and the baseline of curve is almost flat. It represents the mixture of smaller and larger particles present in the sample [14]. This can be understood by referring to the polydispersity index (PdI) value of 0.469 indicating that distribution size of nanoparticles is in the medium range. This medium PdI value also indicates the presence of larger particles after milling since the plant material is hard to grind below $100 \mathrm{~nm}[11,12$, 15] due to the fibrous structure of plant material and limits the size reduction of particle [16].

The surface morphology between nanoparticles and microparticles ground powders was shown in Figure 3. The nanopowders showd a significant difference in size compare to the micropowder which indicates that the size reduction of particles occurred through high impact forces as a consequence of the collision of high accelerated beads and wall of grinding jar. Redispersibility of agglomerated particles to individual particles is another important feature in nanotechnology and extraction process specifically. The particles that readily exist in the individual form will have a greater surface area compared to the agglomerated particles and will affect extraction efficiency by increasing the contact ratio between solvent and particles. Thus, the determination of the degree of redispersibility of freeze-dried nanopowders was carried out. The measurement was carried out by dispersing nanopowders in one-minute ultrasonic time and the suspension was measured as stated earlier. Figure 4 shows the size distribution comparison between nanopowders in the suspension and nanopowders after freeze-drying process. As can be seen in Figure 4, the majority sizes of freezedried nanopowders located at microsize range $(>1000 \mathrm{~nm})$ compared to the size of nanopowders before freeze-drying. This indicates that after solvent removal the particles start to agglomerate. During freezing step, phase separation occurs between the aqueous phase and nanoparticles. This separation between water and nanoparticles will enhance the interaction between them leading to their aggregation or fusion [17].

3.2. HPLC Analysis of Asiaticoside and Asiatic Acid. HPLC chromatograms were shown in Figure 5. As can be seen from chromatogram, asiaticoside and asiatic acid were well resolved with this method and the retention time is 8.807 and 23.809 mins, respectively. Both extracts show many polar compounds appearing in the first 10 minutes since water is very polar solvent; thus it is easy to extract polar compound. This explained why asiaticoside is more preferably extracted in a water extraction compared to the asiatic acid. This low water extraction yield of asiatic acid was in line with what was early reported in $[8,18-20]$. Micropowders extract shows the existing of asiaticoside $\left(t_{R}=8.324 \mathrm{mins}\right)$ and asiatic acid $\left(t_{R}=22.951\right.$ mins $)$ while nanopowders extract shows the disappearance of asiaticoside peaks and only asiatic acid $\left(t_{R}=21.884 \mathrm{mins}\right)$ peaks exist in the analysis. The hydrolysis

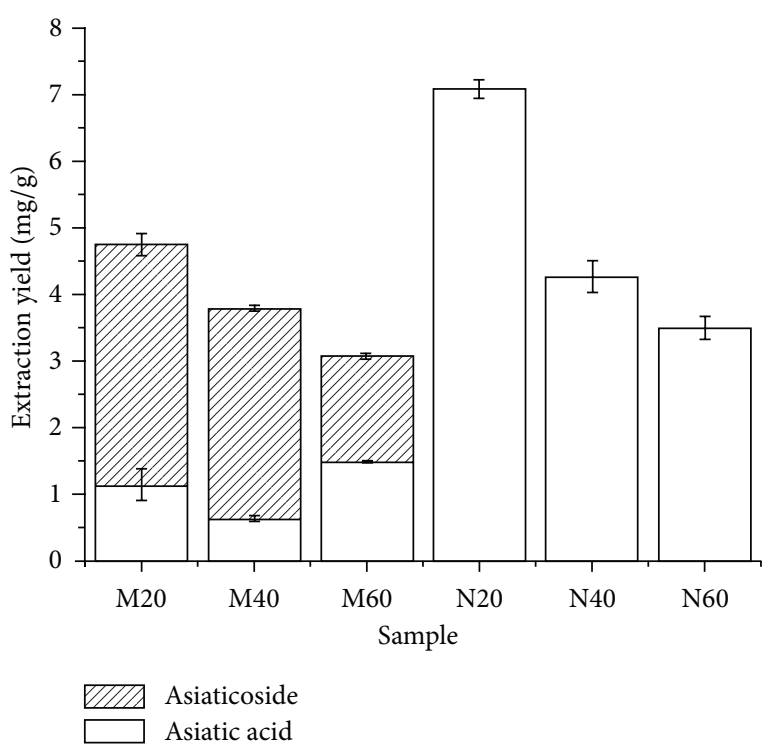

FIGURE 6: The effect of ultrasonic extraction time on the yield of asiaticoside and asiatic acid using micropowders $(M)$ and nanopow$\operatorname{ders}(N)$.

of asiaticoside merely occured in the presence of acid or base as early reported. In this study, we also try to figure out how hydrolysis of asiaticoside occurs in the milling process; this possible mechanism will be explained later in the next section.

To investigate the influence of extraction time on yield of asiaticoside and asiatic acid, sample was extracted at the conditions of $25^{\circ} \mathrm{C}, 125 \mathrm{~W}$, and $50 \mathrm{~mL}$ water at different times $(20,40$, and $60 \mathrm{~min})$. Figure 6 showed that the extraction yield of the asiaticoside and asiatic acid decreased with the increase of extraction time. The extraction yields of active compound for micropowders and nanopowders at $20 \mathrm{~min}$ were 4.75 and $7.09 \mathrm{mg} / \mathrm{g}$, respectively. Increasing extraction time from 20 to $60 \mathrm{~min}$, the extraction yields of asiaticoside and asiatic acid in the micropowders and nanopowders were reduced to 3.07 and $3.49 \mathrm{mg} / \mathrm{g}$, respectively. This is maybe due to degradation of bioactive compound under a long period of exposure to ultrasound activity. Ultrasound extraction through high-energy sound wave induces cavitation and destroys plant cells promoting the penetration solvent to dissolve of target constituent of plant [21]. As extraction time increases, the number of ruptured plant cell increases and results in increasing extraction yield. Nevertheless, increasing number of ruptured plant cell will also increase insoluble compound such as insoluble substances and cytosol suspend in the extraction liquid which will affect the permeability of the solvent [22]. Beside that readsorption of interested compound on the flake of plant particles will also contribute to the low extraction yield at longer time of extraction time [23]. Therefore, it is not necessary to do overtime extraction when the maximum extraction yield has been achieved and thus 20 minutes of extraction time was selected for extraction time. 


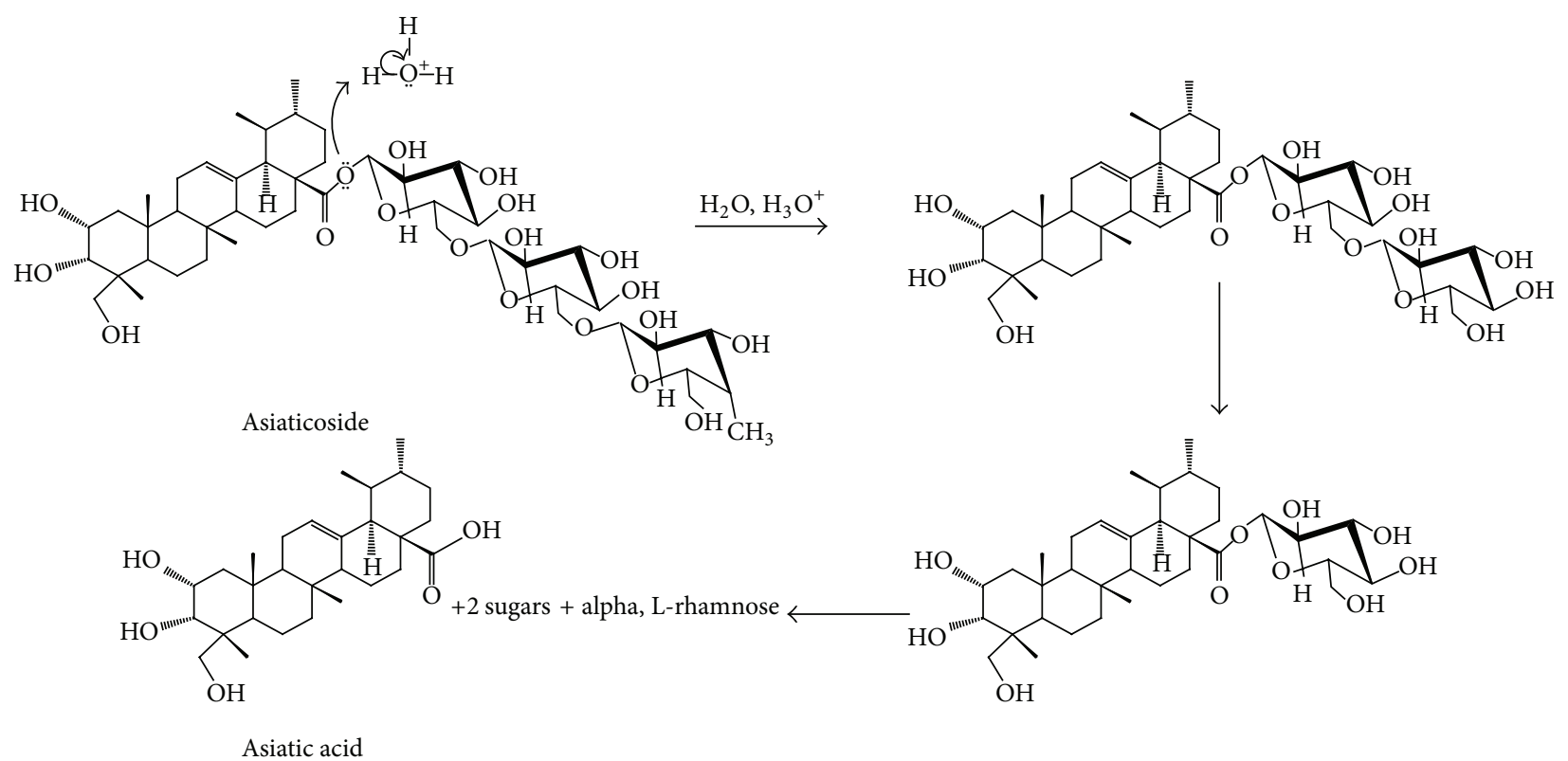

FIgURE 7: Possible mechanism of hydrolysis of asiaticoside.

As can be seen in Figure 6, extraction of asiatic acid in nanopowders is higher than asiatic acid in micropowders at different ultrasonic times. Some asiatic acid in nanopowders might come from hydrolysis of asiaticoside; thus, to be fair, the total of asiaticoside and asiatic acid extracted was used as a comparison to expose the useful application of nanopowders on the extraction yield. Figure 6 also revealed a total asiaticoside and asiatic acid extracted in micropowders was much lower with $4.75 \mathrm{mg} / \mathrm{g}$ compared to the nanopowders with $7.09 \mathrm{mg} / \mathrm{g}$. By using nanopowders, the water extraction yield of bioactive compounds from Centella asiatica could be improved by $49.26 \%$ and almost $50 \%$ improvement. Since nanopowders have higher surface area due to the smaller particles size, then it will help to increase the contact ratio between cell and solvent. With the help of ultrasonic energy, the disruption of cell wall becomes easy $[10,24]$. This action results in surface peeling, erosion, and particle breakdown [25]; thus, nanopowders used in this extraction help speed up the rupture of cell wall and increase the mass transfer of bioactive compounds from cell cytoplasm to the surrounding solvent.

3.3. Possible Hydrolysis Mechanism in Milling Process. Production of asiatic acid from asiaticoside can be easily produced by hydrolyzing asiaticoside in acidic conditions. The explanation of hydrolysis of asiaticoside was shown in early research paper [6]. Hydrolyzation of asiaticoside through milling process is still not explained yet. Thus, we come out with a possible mechanism that could happen during milling process. The conversion asiaticoside to asiatic acid was converted by the hydronium ion $\left(\mathrm{H}_{3} \mathrm{O}^{+}\right)$generated from the reaction zirconium ligand and water. The formation of zirconium ligand due to the interaction between grinding ball and grinding jar consequently allows the zirconium ion $\left(\mathrm{Zr}^{4+}\right)$ to form complex ion as illustrated in chemical equation (1). Therefore, this allows the hydronium ions to be attacked by the oxygen in the asiaticoside structures during the milling process. The sugar structure was hydrolyzed part by part until producing an aglycone (asiatic acid) as shown in Figure 7. This hydrolysis process will produce aglycone and 2 sugar molecules and one rhamnose [26, 27] which of these compounds are a part of sugar moiety in the asiaticoside structure [28]:

$$
\begin{gathered}
\mathrm{ZrO}_{2}+\mathrm{H}_{2} \mathrm{O} \longrightarrow \mathrm{Zr}\left(\mathrm{H}_{2} \mathrm{O}\right)_{6}^{3+} \\
\mathrm{Zr}\left(\mathrm{H}_{2} \mathrm{O}\right)_{6}^{4+}+\mathrm{H}_{2} \mathrm{O} \longleftrightarrow \mathrm{Zr}\left(\mathrm{H}_{2} \mathrm{O}\right)_{5}(\mathrm{OH})^{3+}+\mathrm{H}_{3} \mathrm{O}^{+}
\end{gathered}
$$

The hydrolysis of glycoside also has been explained in [29]. Several articles have been reported on metal oxides such as titanium dioxide $\left(\mathrm{TiO}_{2}\right)$, silicon oxide $\left(\mathrm{SiO}_{2}\right)$, zeolite, and $\mathrm{ZrO}_{2}$ were capable to act as the solid acid catalyst and has been demonstrated as a catalyst in the reaction of converting complex sugar to simple sugar $[30,31]$. In this method, by using the residue of $\mathrm{ZrO}_{2}$ to generate acidic condition in the milling jar, will it be possible to break the sugar moiety from asiaticoside to produce asiatic acid. The possible mechanism was illustrated below.

\section{Conclusions}

Enhancement of water extraction of asiatic acid yield using nanopowders was investigated in this study assisted by ultrasound energy at different extraction times. Extraction of asiatic acid using nanopowders was compared to micropowders and the results show that the extraction of asiatic acid using nanopowders is $50 \%$ higher compared to the micropowder with $7.09 \mathrm{mg} / \mathrm{g}$ extraction yield. Extraction time was 20 minutes due to the maximum yield was obtained 
at this extraction period. In this research; we also found an interesting finding that is, ball milling process using zirconia bead also has a great potential in hydrolyzing glycosides to their aglycone with fast, efficient, and clean green approach. It may revolutionize the preparation of herbal medicine in the future.

\section{Acknowledgment}

Financial support from Universiti Teknologi MARA (UiTM) is gratefully acknowledged.

\section{References}

[1] B. M. Hausen, "Centella asiatica (Indian pennywort), an effective therapeutic but a weak sensitizer," Contact Dermatitis, vol. 29, no. 4, pp. 175-179, 1993.

[2] F. X. Maquart, G. Bellon, P. Gillery, Y. Wegrowski, and J. P. Borel, "Stimulation of collagen synthesis in fibroblast cultures by a triterpene extracted from Centella asiatica," Connective Tissue Research, vol. 24, no. 2, pp. 107-120, 1990.

[3] W. R. Rush, G. R. Murray, and D. J. M. Graham, “The comparative steady-state bioavailability of the active ingredients of Madecassol," European Journal of Drug Metabolism and Pharmacokinetics, vol. 18, no. 4, pp. 323-326, 1993.

[4] P.-J. Shim, J.-H. Park, M.-S. Chang et al., "Asiaticoside mimetics as wound healing agent," Bioorganic and Medicinal Chemistry Letters, vol. 6, no. 24, pp. 2937-2940, 1996.

[5] B.-S. Jeong, C. K. Young, and E.-S. Lee, "Modification of $\mathrm{C} 2,3,23,28$ functional groups on asiatic acid and evaluation of hepatoprotective effects," Bulletin of the Korean Chemical Society, vol. 28, no. 6, pp. 977-982, 2007.

[6] B.-S. Jeong, K. L. Mi, C. K. Young, and E.-S. Lee, "Modification of $\mathrm{C} 2$ functional group on asiatic acid and the evaluation of hepatoprotective effects," Archives of Pharmacal Research, vol. 30, no. 3, pp. 282-289, 2007.

[7] E. S. Ong, J. S. H. Cheong, and D. Goh, "Pressurized hot water extraction of bioactive or marker compounds in botanicals and medicinal plant materials," Journal of Chromatography A, vol. 1112, no. 1-2, pp. 92-102, 2006.

[8] W.-J. Kim, J. Kim, B. Veriansyah et al., "Extraction of bioactive components from Centella asiatica using subcritical water," Journal of Supercritical Fluids, vol. 48, no. 3, pp. 211-216, 2009.

[9] R. Konwarh, S. Pramanik, D. Kalita, C. L. Mahanta, and N. Karak, "Ultrasonication-a complementary "green chemistry" tool to biocatalysis: a laboratory-scale study of lycopene extraction," Ultrasonics Sonochemistry, vol. 19, no. 2, pp. 292-299, 2012.

[10] S. R. Shirsath, S. H. Sonawane, and P. R. Gogate, "Intensification of extraction of natural products using ultrasonic irradiationsa review of current status," Chemical Engineering and Processing, vol. 53, pp. 10-23, 2012.

[11] P. Y. Ma, Z. Y. Fu, Y. L. Su et al., "Modification of physicochemical and medicinal characterization of Liuwei Dihuang particles by ultrafine grinding," Powder Technology, vol. 191, no. 1-2, pp. 194-199, 2009.

[12] Y. L. Su, Z. Y. Fu, C. J. Quan, and W. M. Wang, "Fabrication of nano Rhizama Chuanxiong particles and determination of tetramethylpyrazine," Transactions of Nonferrous Metals Society of China, vol. 16, pp. S393-S397, 2006.
[13] S. Huang and W. H. Chang, "Advantages of nanotechnologybased Chinese herb drugs on biological activities," Current Drug Metabolism, vol. 10, no. 8, pp. 905-913, 2009.

[14] Dynamic Light Scattering: An Introduction in 30 Minutes, Malvern Instruments, Malvern, Wis, USA, 2005.

[15] P. Ma, Z. Fu, Y. Su, and J. Ma, "Nano pulverization of traditional Chinese medicine Liuwei Dihuang," Journal Wuhan University of Technology, vol. 21, no. 2, pp. 105-108, 2006.

[16] R. Rajkhowa, L. Wang, J. Kanwar, and X. Wang, "Fabrication of ultrafine powder from eri silk through attritor and jet milling," Powder Technology, vol. 191, no. 1-2, pp. 155-163, 2009.

[17] W. Abdelwahed, G. Degobert, S. Stainmesse, and H. Fessi, "Freeze-drying of nanoparticles: formulation, process and storage considerations," Advanced Drug Delivery Reviews, vol. 58, no. 15, pp. 1688-1713, 2006.

[18] N. R. Barbosa, F. Pittella, and W. F. Gattaz, "Centella asiatica water extract inhibits iPLA2 and CPLA2 activities in rat cerebellum," Phytomedicine, vol. 15, no. 10, pp. 896-900, 2008.

[19] M. C. Kwon, W. Y. Choi, Y. C. Seo et al., "Enhancement of the skin-protective activities of Centella asiatica L. urban by a nanoencapsulation process," Journal of Biotechnology, vol. 157, no. 1, pp. 100-106, 2012.

[20] A. Soumyanath, Y.-P. Zhong, E. Henson et al., "Centella asiatica extract improves behavioral deficits in a mouse model of Alzheimer's disease: investigation of a possible mechanism of action," International Journal of Alzheimer's Disease, vol. 2012, Article ID 381974, 9 pages, 2012.

[21] T. J. Mason, L. Paniwnyk, and J. P. Lorimer, "The uses of ultrasound in food technology," Ultrasonics Sonochemistry, vol. 3, no. 3, pp. S253-S260, 1996.

[22] S. Zhao, K.-C. Kwok, and H. Liang, "Investigation on ultrasound assisted extraction of saikosaponins from Radix Bupleuri," Separation and Purification Technology, vol. 55, no. 3, pp. 307312, 2007.

[23] J. Dong, Y. Liu, Z. Liang, and W. Wang, "Investigation on ultrasound-assisted extraction of salvianolic acid B from Salvia miltiorrhiza root," Ultrasonics Sonochemistry, vol. 17, no. 1, pp. 61-65, 2010.

[24] M. Vinatoru, "An overview of the ultrasonically assisted extraction of bioactive principles from herbs," Ultrasonics Sonochemistry, vol. 8, no. 3, pp. 303-313, 2001.

[25] L. Paniwnyk, H. Cai, S. Albu, T. J. Mason, and R. Cole, "The enhancement and scale up of the extraction of anti-oxidants from Rosmarinus officinalis using ultrasound," Ultrasonics Sonochemistry, vol. 16, no. 2, pp. 287-292, 2009.

[26] B. Burlando, L. Verotta, L. Cornara, and E. Bottini-Massa, Herbal Principles in Cosmetics: Properties and Mechanisms of Action, Taylor \& Francis Group, 2010.

[27] C. K. Kokate, A. P. Purohit, and S. B. Gokhale, Pharmacognosy, NIRALI PRAKASHAN, 2009.

[28] D. Monti, A. Candido, M. M. Cruz Silva, V. Křen, S. Riva, and B. Danieli, "Biocatalyzed generation of molecular diversity: selective modification of the saponin asiaticoside," Advanced Synthesis and Catalysis, vol. 347, no. 7-8, pp. 1168-1174, 2005.

[29] T. W. G. Solomons and C. B. Fryhle, Organic Chemistry, John Wiley \& Sons, 9th edition, 2008.

[30] H. Wang, C. Zhang, H. He, and L. Wang, "Glucose production from hydrolysis of cellulose over a novel silica catalyst under hydrothermal conditions," Journal of Environmental Sciences, vol. 24, no. 3, pp. 473-478, 2012.

[31] K. D. O. Vigier and F. Jérôme, Heterogeneously-Catalyzed Conversion of Carbohydrates, vol. 295, 2010. 

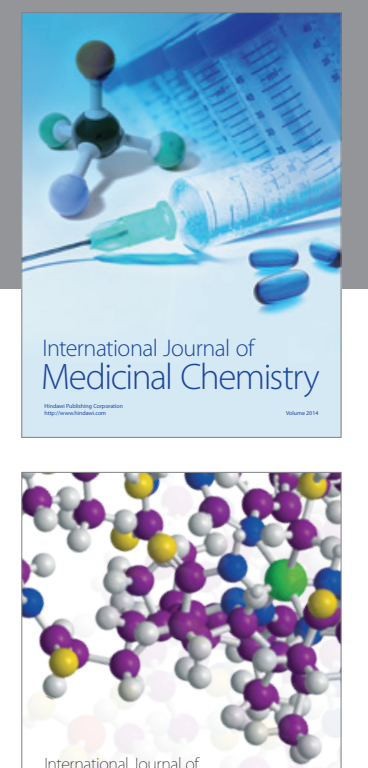

\section{Carbohydrate} Chemistry

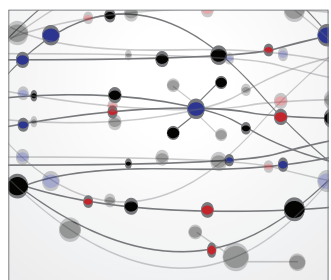

The Scientific World Journal
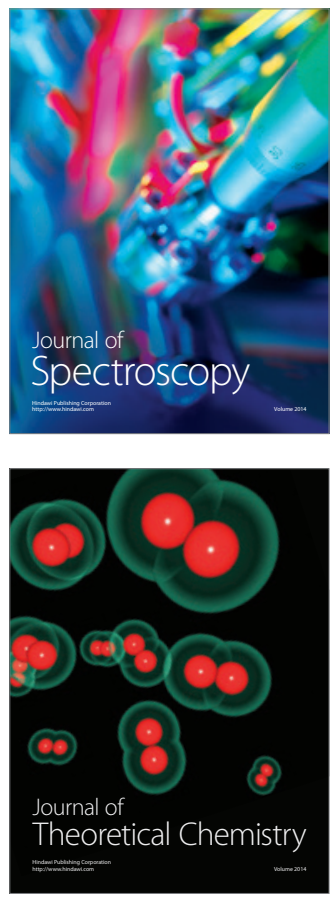
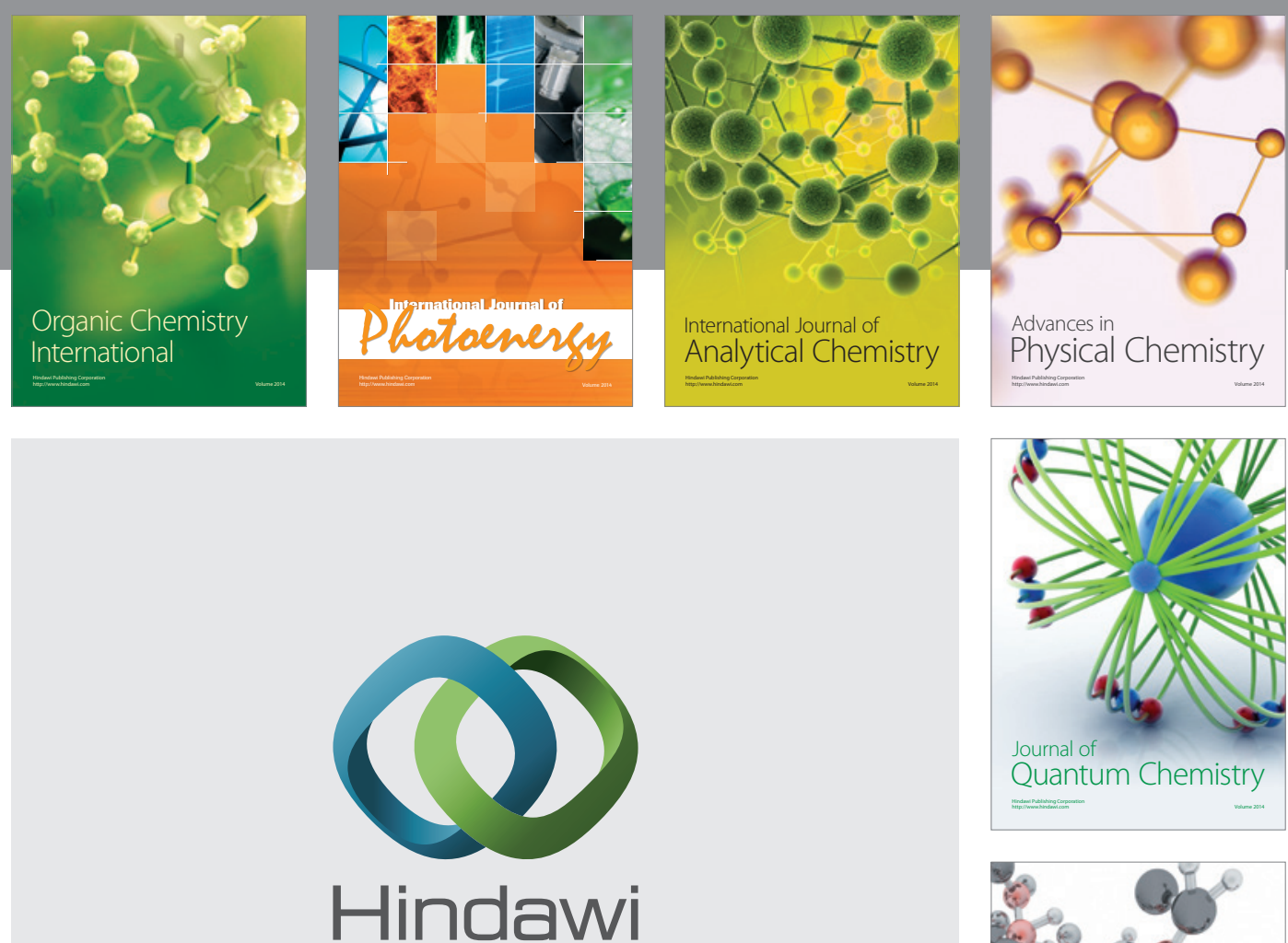

Submit your manuscripts at

http://www.hindawi.com

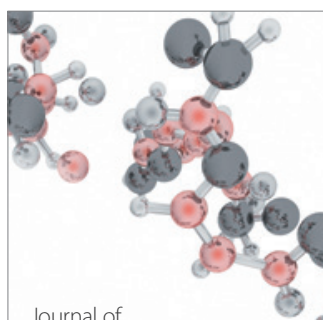

Analytical Methods

in Chemistry

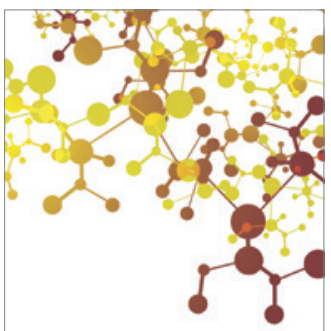

Journal of

Applied Chemistry

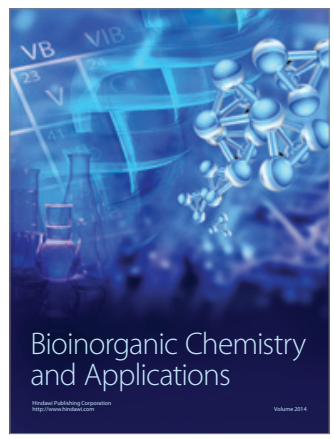

Inorganic Chemistry
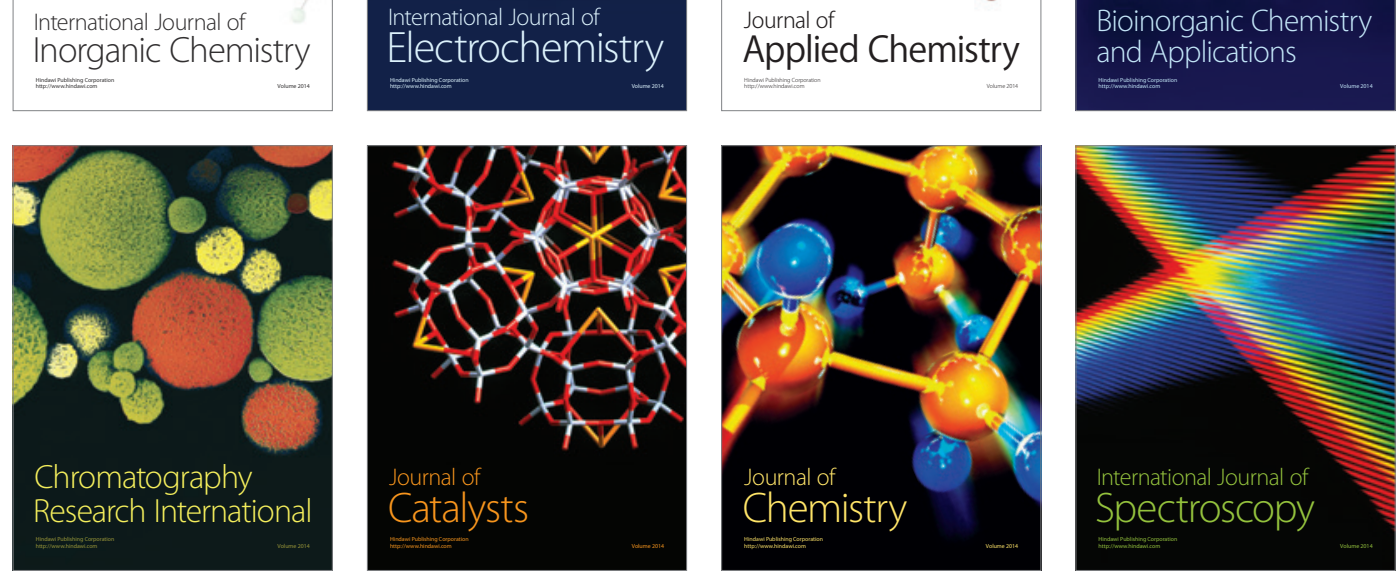